ISSN: 0213-2087 e-ISSN: 2444-7080

DOI: https://doi.org/10.14201/shhcont382020243264

\title{
BREVE REVISIÓN DE LOS PROCESOS \\ DE RESISTENCIA CONTRA LA COLONIZACIÓN \\ EN EL CUERNO DE ÁFRICA. \\ LAS LUCHAS EN LA SOMALIA ITALIANA \\ Y EL MOVIMIENTO DERVICHE (1890-1930)
}

\author{
Brief review of the processes of resistance \\ against colonization in the Horn of Africa. \\ Struggles in Italian Somalia \\ and the Dervish Movement (1890-1930)
}

\author{
Pablo ARCONADA LEDESMA \\ Universidad de Valladolid \\ pablo.arconada@uva.es \\ ORCID: 0000-0003-4068-274X
}

Recibido: 29/02/2020 Revisado: 25/05/2020 Aceptado: 15/06/2020

RESUMEN: Este artículo tiene la intención de revisar las resistencias contra el proceso de colonización que se desarrollaron en el Cuerno de África en el período 1890-1930. Específicamente, se analizarán las luchas impulsadas por los pueblos somalíes en las diferentes regiones ocupadas. El objetivo no es otro que repensar la imagen de los somalíes como "pueblos pasivos" que "se dejaron conquistar" y analizar los acontecimientos con otra perspectiva radicalmente diferente. Además, si tradicionalmente se ha considerado que la única resistencia digna de ser considerada fue el Movimiento Derviche, en este estudio se ha procedido a analizar también el papel de otros movimientos de resistencia que se sucedieron en el sur de Somalia y en los sultanatos de Obbia y Midyurtina, así como el caso específico de las Revueltas Gosha. Para realizar este estudio se ha procedido a una revisión bibliográfica y se han utilizado fuentes primarias y secundarias como documentación oficial, tratados y diarios, así como boletines informativos de la época y la hemeroteca.

Palabras clave: Somalia; Gosha; Derviche; Benadir; colonización. 
ABSTRACT: This article intends to review the resistance against the colonization process that developed in the Horn of Africa in the period 1890-1930. Specifically, it will analyse the struggles driven by the Somali peoples in the different occupied regions. The objective is to rethink the image of the Somalis as "passive peoples" who "allowed themselves to be conquered" and to analyse events from another radically different perspective. Furthermore, if traditionally the only resistance worthy of consideration was the dervish movement, this study has also proceeded to examine the role of other resistance movements that took place in southern Somalia and in the Sultans of Obbia and Midyurtina, as well as the specific case of the Gosha Revolts. To carry out this study, a bibliographical review was carried out and primary and secondary sources were used as official documentation, treatises, and journals, as well as newsletters of the time and the newspaper library.

Key words: Somalia; Gosha; Dervish; Benadir; colonization.

\section{INTRODUCCIÓN}

El reparto y la colonización de África por parte de las potencias europeas repercutió en muchos pueblos del continente. Esta ocupación provocó una alteración de las estructuras políticas, económicas, sociales y culturales africanas y marcó su desarrollo a lo largo de todo el siglo XX. La historia escrita por "los vencedores» ha desterrado durante décadas el carácter más activo de los pueblos africanos. La misma situación se reprodujo en el Cuerno de África ya que los pueblos somalies hicieron frente durante décadas a la ocupación colonial.

Tradicionalmente el Movimiento de los Derviches (1899-1920), encabezado por el Mullab Maxamed Cabdille Xasan, ha ocupado la mayoría de los escritos sobre la resistencia somalí. Sin embargo, no podemos pasar por alto que existieron otras formas de oposición en esta región. Entre ellas destacan algunos ejemplos como la resistencia Benadir, también conocida como Revuelta Bimaal (1896-1924), las Revueltas Gosha (1890-1907) y las resistencias de los sultanatos de Obbia y Midyurtina (1923-1927). Precisamente, este artículo tiene el objetivo de analizar de forma holística los diferentes tipos de resistencias que existieron en el Cuerno de África con el objetivo último de repensar no sólo su papel, sino cómo se han analizado estos procesos desde la visión de la disciplina histórica.

\section{El REPARTO DEL CUERNO DE ÁFrica y los EFECTOS DE LA OCUPACIÓN}

La Conferencia de Berlín (1884-1885) marcó un antes y un después en el proceso colonizador pero, a pesar de lo que suele pensarse, no generó de forma directa una división territorial del continente ${ }^{1}$. Así, se puede decir que la colonización no fue dibujada

1. Ceamanos, Roberto: El reparto de África. De la Conferencia de Berlín a los conflictos actuales. Madrid: Los Libros de la Catarata, 2016, pp. 44-45 
en un mapa en Berlín, sino que se fue desarrollando dependiendo de los sucesos que tenían lugar en el continente africano y de la expansión de los imperios coloniales².

Fue en este contexto en el que las diferentes potencias europeas se fueron aproximando al Cuerno de África. La cercanía de la India y la apertura del Canal de Suez en 1869 llevaron a estos países a asentarse en la región ${ }^{3}$. Así, los franceses establecieron un protectorado en 1885 en el actual Yibuti e Italia tomó el control de algunas ciudades costeras del sur de Somalia en 1888, momento en el cual proclamó su control sobre la costa, creando sendos protectorados en los sultanatos de Obbia y Midyurtina en $1889^{4}$. Los británicos firmaron tratados con diferentes clanes en la zona de Berbera entre 1884-1885 a excepción de los warsangali que concluyeron su tratado en 1886 en Dolbahanta5.

Por su parte, Etiopía también se lanzó a controlar parte de los territorios habitados por población somalí como respuesta al avance europeo en la región ${ }^{6}$. Lo cierto es que el emperador Menelik II, que gobernó hasta 1913 y convirtió al país en una potencia centralizada, poderosa y moderna ${ }^{7}$, aplicó una política expansiva de tal manera que puso bajo su control los sultanatos somalíes de Harar y de Ausa en el noreste del Cuerno de África hacia 1887 y llegó incluso a rozar el río Jubba en $1897^{8}$.

De este modo, para finales del siglo XIX, los pueblos del Cuerno de África ya habían comenzado a notar los efectos de la colonización. Debemos tener en cuenta que los somalíes formaban una comunidad bien definida con una lengua, una cultura, una religión y unas formas de vida comunes, pero no un conjunto político 9 . Esta unidad es producto de la percepción de un origen mitológico común que se relaciona con la descendencia por línea directa del antepasado Samaal y la casa del profeta Mahoma.

Así, el sistema de clanes se construye sobre la relación de parentesco, pero los lazos que unen a los parientes consanguíneos se basan en un contrato social, en un sistema público de reglas negociadas ${ }^{10}$. Igualmente, los diferentes clanes de Somalia contaban con instituciones de gran importancia como el xeer en el que se resolvían

2. García Moral, Eric: Breve Historia del África Subsahariana. Madrid: Nowtilus, 2017, p. 161.

3. Yusuf ABDi, S.: "Decolonization in the Horn and the Outcome of Somali Aspirations for Selfdetermination». Northeast African Studies,2, 1981, pp. 153-162, esp. p. 154.

4. Iвrahim, H.A.: "African initiatives and resistance in North-East Africa». En: Adu BohaEn, A. (ed.): General History of Africa VII: Africa under colonial domination 1880-1935. UNESCO: Paris, pp. 63-86, esp. p. 82.

5. Hamilton, Angus: Somaliland. London: Hutchinson and Co, 1911, p. 45.

6. Iвrahim H.A.: "African initiatives and resistance...", op. cit., p. 82.

7. Wezzeling, Henri: Divide y vencerás: el reparto de África, 1880-1914. Barcelona: Península, 1999, p. 293.

8. Caranci, Carlo: "El pansomalismo: claves históricas del conflicto del Cuerno de África", África Internacional, 5-6, 1988, pp. 193-212.

9. Yusuf ABDi, op. cit., p. 153.

10. Jama, Mohamed: "Kinship and Contract in Somali Politics", Africa: Journal of the International African Institute, 77, 2007, pp.226-249, esp. p. 226. 
las cuestiones políticas y el xeerbeegti donde se mediaba por las disputas legales y funcionaba como un instrumento para resolver conflictos ${ }^{11}$. No obstante, la existencia de estas instituciones no impidió los enfrentamientos. Tampoco debemos suponer que estas instituciones con carácter decisorio fueran el producto de una autoridad centralizada que regulara las relaciones entre grupos opuestos ${ }^{12}$. Aunque los somalíes tenían una organización bastante definida, eso no quería decir que estuvieran unidos políticamente. Como ya indicó Lewis:

los somalíes siempre han constituido una nación, pero el nacionalismo político fue inexistente hasta la ocupación efectiva del territorio por los imperios. La división de la península por fuerzas no-musulmanas en diferentes territorios [...] reforzó los sentimientos de la identidad nacional a través del islam ${ }^{13}$.

Efectivamente, las estructuras políticas fueron las primeras en verse alteradas por la llegada de los europeos que modificaron el orden político previo. Si bien es cierto que algunos modelos de colonización como el inglés y su indirect rule ${ }^{14}$ "respetaron" algunas estructuras tradicionales, lo cierto es que las fuerzas coloniales fueron modificando algunas características de las instituciones tradicionales. Así, introdujeron en algunas zonas de Somalia un sistema centralizado que dejó todos los poderes efectivos en las manos de los administradores coloniales, cediendo sólo los puestos de poder más bajo a los somalíes. Los jefes elegidos, conocidos como akils por el protectorado británico y capos en la Somalia dominada por Italia, actuaban sólo como consejeros ${ }^{15}$. Asimismo, la firma de tratados para delimitar las fronteras entre las diferentes potencias coloniales, incluida Etiopía, marcó un antes y un después en la movilidad de la población. Aunque esto no hizo que los movimientos transfronterizos desaparecieran, el cruce de fronteras se complicó en algunas regiones. En este aspecto tuvo mucho que ver también la Etiopía imperial que, a través de diferentes pactos con los europeos, acabó reconfigurando el mapa regional. Esto fue visible en los tratados firmados por Etiopía y Gran Bretaña ${ }^{16}$, así como con Francia ${ }^{17}$ en 1897; los acuerdos firmados entre

11. Ibid. p. 228.

12. LEWIS, Ioan Myrddin: "Pan-Africanism and Pan-Somalism", The Journal of Modern African Studies, 1, 1963, pp.147-161, esp. p. 147.

13. Ibid., p. 148.

14. Mamdani, Mahmood: "Historicizing Power and Responses to Power: Indirect Rule and its Reforms", Social Research, 66(3), 1999, pp. 859-886, esp. p. 870.

15. Ibrahim, H.A.: "Politics and Nationalism in North-East Africa 1919-1935». En: Adu Bohaen, A. (ed.): General History of Africa VII: Africa under colonial domination 1880-1935. París: UNESCO, 1985, pp. 580-602, esp. p. 596.

16. Rennell Rodd, J.: Social and Diplomatic Memories, 1894-1910, Edward Arnold \& Co, Londres, 1923, pp. 1162-191. Disponible en: https://archive.org/details/socialdiplomatic00rodduoft/page/n8, [Consultado el 31 de julio de 2019].

17. Marcus, H.G.: "The Foreign Policy of the Emperor Menelik 1896-1898", The Journal of African History, 7, 1966, pp. 117-122, esp. p. 119. 
Gran Bretaña, Francia e Italia en 1906 18 ; y finalmente el pacto italo-etíope de $1908^{19}$. Todos estos acuerdos consolidaron nuevas fronteras y dibujaron una nueva realidad que afectó directamente a los pueblos somalíes que quedaron divididos entre diferentes entidades estatales.

Por otra parte, se malinterpretaron las identidades del Cuerno de África. La visión europea exageró la valoración desmedida de los africanos por la costumbre y la continuidad, olvidando que esta podía ser flexible. Algunos autores han enfatizado que, lejos de haber una sola identidad, la mayoría de los africanos entraron y salieron de múltiples identidades. Por lo tanto, los límites que los europeos pusieron a las jerarquías de autoridad no coincidían con la realidad ${ }^{20}$. Así, la concepción europea transformó las instituciones y las organizaciones tradicionales, haciéndolas mucho más rígidas de lo que en realidad podían ser. Los administradores coloniales no entendieron la política tradicional somalí, creyeron que los akils, por ejemplo, controlaban la sociedad tradicional a través de los lazos étnicos ${ }^{21}$ cuando, en realidad, eran estructuras poco o nada jerarquizadas donde los líderes tenían un papel eminentemente representativo. A este respecto, Said Yusuf Abdi definió la sociedad somalí como una nación unida por un sistema político descentralizado basado en los xeer (asambleas de clanes)22.

Además de lo político, la población somalí se vio afectada en lo económico. Madeira Santos, en relación con lo que aconteció en el continente, expresó que la mayor parte de las alteraciones experimentadas a finales del siglo XIX estuvieron muy unidas a las modificaciones del volumen y de las estructuras comerciales y, naturalmente los sistemas económicos en los que se basaban ${ }^{23}$. La naturaleza del colonialismo capitalista llevó a la economía colonial a absorber los sistemas económicos del Cuerno de África, eliminando el control de los medios de producción tradicionales. Esto obligó a la sociedad somalí a adaptarse a los cambios. De este modo, los comerciantes somalíes y los corredores de ganado (dizaals) tuvieron que aprender a coexistir con las formaciones sociales

18. Robertson, J.C.: "British Policy in East Africa, March 1891 to May 1935", The English Historical Review, 93, 1978, pp. 835-844, esp. p. 836.

19. Stern, W.B.: "The Treaty Background of the Italo-Ethiopian Dispute", The American Journal of International Law, 30 1936, pp. 189-203, esp. p. 194.

20. Ranger, Terence: "The Invention of Tradition in Colonial Africa». En: Hobsbawm, Eric y Ranger, Terence (eds.): The Invention of Tradition. Cambridge: Cambridge University Press, 2000, pp. 211-262, esp. pp. 247-248.

21. JAMA, Mohamed, op. cit., p. 229.

22. Yusuf AbDi, S: "Decolonization in the Horn and the Outcome of Somali Aspirations for Selfdetermination". Northeast African Studies,2, 1981, pp. 153-162, esp. p. 153.

23. Madeira Santos, M.E.: "História da África: Relaçao Europa - África no Terceiro Quartel do Século XIX - Notas Introdutórias». En: MadeIRA SAnTos, M.E. (ed.): Actas: I Reuniâo Internacional de História de Africa: relaçao Europa-Africa. Lisboa: Instituto de Investigaçao Científica Tropical, 1989, pp. 9-17. 
capitalistas $^{24}$. Tal fue el caso de los grupos pastoriles que, al igual que los pescadores, estaban totalmente inmersos en la economía monetaria colonial hacia $1920^{25}$.

Por último, hay que tener en cuenta que la maquinaria colonial también supuso un choque cultural sin precedentes. Muchas de las resistencias que tuvieron lugar a finales del siglo XIX se opusieron a la alteración de los usos y costumbres tradicionales de Somalia, así como a la relajación de la fe.

\section{Las ReACciones de los pueblos de Somalia. Las REVUeltas de la Somalia italiana Y EL ESTADO DeRVICHE}

África no fue un continente inmóvil. Debemos hacer frente a esa imagen extendida de los africanos como pueblos pasivos que, debido a su «subdesarrollo» $\mathrm{y}$ "atraso tecnológico", se dejaron conquistar por la "superioridad» europea. Frente a esto, en todas las regiones del continente la población creó mecanismos de enfrentamiento, resistencia y lucha con los que intentaron paliar la ventaja armamentística europea. Las luchas se prolongaron varios años, lo que se reflejó en rebeliones de todo tipo ${ }^{26}$. Aunque hubo casos en que las élites negociaban y pactaban con los colonizadores, en un primer momento las resistencias fueron lideradas por esas minorías privilegiadas. Si bien, no tardaron en aparecer diferentes resistencias populares que cristalizaron en varias modalidades, desde la huida a la lucha armada ${ }^{27}$. Este hecho estuvo muy presente también en el Cuerno de África donde los pueblos somalíes se enfrentaron a la ocupación de italianos, británicos, franceses y etíopes. En esta investigación nos centramos muy especialmente en analizar los procesos de resistencia surgidos en la Somalia italiana y la británica, dejando al margen el caso de la Somalilandia francesa, hoy Yibuti, por su particularidad al convivir dos pueblos de orígenes diferentes: los issa, clan somalí, y los afar, vinculados a los pueblos etíopes ${ }^{28}$.

24. Geshekter, C.L.: "Anti-Colonialism and Class Formation: The Eastern Horn of Africa before 1950", The International Journal of African Historical Studies, 18, 1985, pp. 1-32, esp. p. 19.

25. Rodney, Walter: "The colonial economy». En: Adu Bohaen, Albert (ed.): General History of Africa VII: Africa under colonial domination 1880-1935. París: UNESCO, 1985, pp. 332-350, esp. p. 343.

26. García Moral, Eric, op. cit., pp. 164-182.

27. Ki-Zerbo, Joseph: Historia del África Negra. De los orígenes a las independencias. Barcelona: Edicions Bellaterra, 2011, p. 617.

28. Arconada Ledesma, Pablo: «El proceso de descolonización en Yibuti: entre la influencia de Francia y la disputa etíope-somalí (1958-1977)». En: GARcía ANDrés, César; CuAdrado Bolaños, Jara y ArCONADA LEDESMA, Pablo (eds.): África, un continente en transformación. Enfoques Interdisciplinares. Valladolid: Ediciones Universidad de Valladolid, 2020, pp. 87-103. 


\subsection{Lucha y resistencia en la Somalia italiana}

Los acuerdos anglo-italianos de 1891 otorgaron a Italia una zona de influencia importante en la costa sur de Somalia. Sin embargo, no fue hasta después del final de la Primera Guerra Mundial cuando logró consolidar su dominio sobre estos territorios. Todos los intentos anteriores al conflicto mundial fueron en vano debido a la alta resistencia de las poblaciones ribereñas del sur que se convirtió, a finales del siglo XIX, en un centro de resistencia económica y religiosa frente a la colonización italiana ${ }^{29}$, así como los antiguos sultanatos de la región y los gosha, que se caracterizaron por luchar contra la esclavitud y la ocupación italiana. A pesar de ello, algunos medios italianos de la época hacían referencia ya en 1885 a la gran misión de Italia en el continente africano:

Italia, constituida como nación, envió por primera vez a sus soldados fuera de la patria. Esos buenos soldados [...] incitarán con certeza, en las poblaciones bárbaras, el respeto y la admiración de nuestra Italia. [...] La expedición de las tropas italianas en África es el primer paso de un nuevo periodo histórico para la patria [...] la mirada de la nación se dirige a África, donde nuestros hermanos han ido a proteger el honor nacional ${ }^{30}$.

Las primeras expediciones a la zona de Somalia se empezaron a organizar ya en 1886 cuando:

El 26 de enero, ha partido de nuestro puerto la Compañía General de Navegación Italiana, con el componente de la expedición científico-comercial que, bajo la dirección del conde Gian Pietro Porro, se aproximará a la ciudad de Harar y al país somalî31.

Es evidente el discurso nacionalista de la época y a pesar de la gran esperanza de constituirse de nuevo en un imperio, Italia tuvo que hacer frente a las grandes resistencias de Somalia que, como veremos, se alargarán hasta casi 1930.

\subsubsection{Las resistencias del sur de Somalia (1896-1924)}

Como ya hemos comentado antes, la zona sur de Somalia, entre los ríos Shabelle y Jubba y en la denominada costa Benadir, que abarca desde Mogadiscio hasta el puerto de Kisimayo, fue una zona que mantuvo una férrea oposición a la colonización italiana. Aunque parezca un debate poco fértil, es importante analizar las fuentes y tratar de

29. Haji Mukhtar, Mohamed: "The Plight of the Agro-Pastoral Society of Somalia", Review of African Political Economy, 23(70), 1996, pp. 543-553, esp. p. 545

30. Della Valle: «L'Italia en Africa», Bollettino della Società Africana D'Italia, Anno IV, Fasc. I, 1885, pp. 3-4. Disponible en: http://digitale.bnc.roma.sbn.it/tecadigitale/giornale/TO00085004/1885/unico [Consultado el 24 de febrero de 2020].

31. S.a.: "Spedizione per l'Haraar ed I paesi somali», Bollettino della Società Africana D'Italia, Anno V, 1886, pp. 13-14, Disponible en: http://digitale.bnc.roma.sbn.it/tecadigitale/giornale/TO00179105/1886/ unico [Consultado el 24 de febrero de 2020]. 
determinar cuál sería la acepción más acertada para referirnos al conglomerado de movimientos de resistencia que se generaron en esta región.

Tradicionalmente se ha unido a todos los grupos de la región bajo el mismo término, lo que responde a que compartieron un espacio y un tiempo común. Esta oposición, conocida como resistencia Benadir o Revuelta Bimaal, tuvo lugar entre 1896 y 1924, es decir, mantuvo una lucha abierta frente a los italianos con momentos de mayor alcance antes y durante la Primera Guerra Mundial. Algunos autores, como Guadagni ${ }^{32}$, utilizaron el término bimaal para referirse a todo el proceso de resistencia de la región del sur de Somalia, aglutinando las diferentes resistencias bajo este nombre. Esto se debió sin duda a que los bimaal fueron uno de los principales grupos que lucharon contra la invasión italiana y fomentaron una oposición armada. Sin embargo, debemos pensar que estos eran sólo un pequeño pueblo, perteneciente al clan dir, y no sería justo englobar al total de una región bajo su término. Otros autores, como Caranci, se refirieron a la diversidad de pueblos que se enfrentaron a los italianos: «entre 1905 y 1908 es el turno de los bimaal, entre 1911-1912 es el de los galdyal y las tribus del Shabelle...”33.

Por tanto, podría parecer mucho más acertado referirnos a estos movimientos de oposición como resistencias Benadir, ya que se ha utilizado como término geográfico que engloba el territorio que va desde Mogadiscio hasta la desembocadura del río Shabelle. Sin embargo, algunos grupos de población de la zona se conocen también como benadiri, lo que nos podría llevar a una nueva confusión. Por ello, desde aquí proponemos el uso de términos plurales, que engloben la diversidad en tiempo, características y formas de actuación de cada movimiento de resistencia que convivieron en el sur de Somalia. Por ello, quizás la mejor expresión podría ser «resistencias del sur de Somalia». Esto crearía además una diferencia clara con las resistencias de los sultanatos de Obbia y Midyurtina que más tarde analizaremos.

Aunque el término con el que referirnos a estos procesos no está claro, parece que la fecha de inicio de la resistencia sí lo está. En general, se ha considerado como punto de partida de estas resistencias el año 1896. En ese año tuvo lugar la llamada batalla de Lafole, una reyerta protagonizada por un grupo de agricultores locales que se unieron para asaltar una expedición italiana que iba de Mogadiscio a Gheledi. Aunque la cantidad de bajas resulta ínfima si lo comparamos con otros enfrentamientos, la importancia radica en la muerte de Antonio Cecchi, el principal promotor del proceso colonizador en Somalia ${ }^{34}$. Esta primera victoria dio alas a todos los movimientos de la región, que mostraron que la población local estaba dispuesta a luchar con los medios

32. Guadagni, Marco: "Colonial Origins of the Public Domain in Southern Somalia (1892-1912)", Journal of African Law, 22, 1978, pp. 1-29, esp. p. 12.

33. Caranci, Carlo, op. cit., p. 193.

34. Guadagni, Marco, op. cit., p. 13. 
que fueran necesarios. No obstante, también demostró que la presencia italiana no iba a pasar por alto el ataque ya que unos meses después:

Lafole y otras dos aldeas cercanas fueron destruidas y alrededor de mil somalíes se dieron a la fuga, sufriendo grandes pérdidas, de las cuales se han comprobado unos cincuenta muertos y un centenar de heridos. Nuestras pérdidas fueron: un jefe muerto y trece heridos. [...] Dos somalíes murieron en el conflicto, que mataron a Cecchi. En las cabañas y pueblos se encontraron objetos pertenecientes a la expedición de Cecchi ${ }^{35}$.

A diferencia del Movimiento de los Derviches, que en su mayoría estuvo compuesto por pueblos nómadas, la mayor parte de las resistencias del sur se organizaron por personas sedentarias, cuyo enfrentamiento contra los europeos se basó en la defensa de la tierra y la economía rural de la zona. En algunos casos estas resistencias se basaron también en motivos religiosos. Por otro lado, algunos autores de la época trataron de justificar el nacimiento de esta resistencia como una oposición local a la política de abolición de la esclavitud impulsada por Italia. Sin negar que este puede ser otro de los motivos, parece que las fuentes italianas de la época hubieran exagerado esta razón con el objetivo de justificar las operaciones militares en Somalia, presentando la colonización ante el Parlamento y la opinión pública como una necesidad para acabar con la esclavitud en la zona. Parece que la razón real de esta regulación no era la libertad de los esclavos, sino la confiscación de tierras y la implantación de trabajos forzados ${ }^{36}$.

El proceso colonizador italiano, pese a lo que suele pensarse, no fue sencillo. De esta manera, entre 1896 y 1920, los benadiri, bimaal, geledi, bin-tire o Wa'dan y las comunidades religiosas o Jama' $a^{37}$, defendieron las regiones ribereñas y se resistieron a la colonización ${ }^{38}$. Los que mayor resistencia opusieron fueron, sin duda, los bimaal que a lo largo del período 1907-1908 plantaron cara al expansionismo italiano que

después del conflicto de Lugh [...] iniciaron en Benadir los trabajos para una ocupación militar efectiva de la zona comprendida entre la costa y el curso bajo del río Shebelle, escenario de las incursiones de los fanáticos y rebeldes bimaal ${ }^{39}$.

35. S.a.: "Gli autori della spedizione Cecchi castigati», Bollettino della Società Africana d'Italia, Anno XVI, Fasc. IV, 1897, pp. 88-89. Disponible en: http://digitale.bnc.roma.sbn.it/tecadigitale/giornale/ TO00179105/1897/ [Consultado el 15 de noviembre de 2019].

36. Guadagni, Marco, op. cit., p. 12.

37. Jama'a hace referencia a un asentamiento agrario, fundado por un líder religioso de uno de los principales órdenes sufi de Somalia: Qadiriyya, Ahmadiyya o Salihiyya. A los Jama’a accedían varones jóvenes y lo hacían de forma voluntaria, además el acceso no dependía del origen del clan. Buscado en: Haji Mukhtar, Mohamed: Historical Dictionary of Somalia. Oxford: Scarecrow Press, 2003, p. 127.

38. KeNDALL, John George: Wiley Blackwell encyclopedia of race, ethnicity and nationalism, 2015.

39. S.a.: «Nel Benadir. Preludi dell'occupazione militare - Due scontri a Sud di Merca. La zona delle future operazionis, Bollettino della Società Africana d'Italia, Anno XXVII, Fasc. VII-VIII, julio-agosto 1908. Disponible en: http://digitale.bnc.roma.sbn.it/tecadigitale/giornale/TO00179105/1908 [Consultado el 26 de enero de 2020]. 
Al parecer el avance hacia el sur, en un principio, fue rápido ya que el 15 de marzo de 1908 uuna columna comandada por el Capitán Vitalia, con 512 hombres, asistidos por los barcos Volta y Staffeta, ocuparon Danane sin encontrar resistencia». Si bien las mayores resistencias a la ocupación se produjeron entre abril y agosto de ese año. De hecho, a mediados de mayo aún el sector entre Merca y Mogadiscio no estaba completamente pacificado ${ }^{40}$.

Otras rebeliones surgidas en la región, al margen de los bimaal, estuvieron dirigidas por guerreros como Sheikh Abdi Abiikar Gaafle y líderes milenaristas como Sheikh Hassan Barsane que se levantaron por la ocupación de los puertos de la $\operatorname{costa}^{41}$. No debemos pensar tampoco en que las resistencias del sur de Somalia llegaran a estar unidas, sino que también hubo enfrentamientos entre diferentes grupos. Precisamente, "Sheikh Abdi Abiikar, primo del sultán de Gheledi, atacó a los bimaal que habían invadido su territorio y los venció matando a 23 de ellos». Además, es evidente que los propios italianos utilizaron el lema divide et impera pues como se registra en ese mismo testimonio: "Los bimaal han pedido la paz, pero Seikh Abdi respondió que no podía hacer la paz con los enemigos del gobierno italiano» ${ }^{42}$.

Quizás por esta división las derrotas no tardaron en llegar y en 1908 se sucedieron diferentes pérdidas que supusieron un duro golpe a los planes de la resistencia. La mayor parte de la costa Benadir cayó en ese mismo año, así como las fuerzas wa'dan o los bimaal que, con un ejército de 2.000 soldados, lucharon contra un ejército de 500 italianos en la batalla de Sabti iyo Ahad (batalla del sábado y el domingo) en la que fueron derrotados ${ }^{43}$. La caída de la ciudad de Mereerey en agosto de 1908 y la derrota de la unión de los hintire y hubeer abrió definitivamente el interior de las regiones ribereñas a los italianos, accediendo a la colonización de las tierras más fértiles de la región ${ }^{44}$. A la derrota de las revueltas en la franja de la costa sur de Somalia refirió el Gobernador de Benadir, Tommaso Carletti, en su diario en 1908:

La ocupación de la línea del río Shabelle ha dado a nuestra colonia refugio de vida y pulmones para respirar, y marca un punto decisivo en la historia de Benadir. A partir de este momento, la vida es nueva. El programa económico toma el relevo del programa político con dos objetivos: el desarrollo del tráfico comercial entre el interior y la Colonia, y entre esta y la madre patria, así como el desarrollo agrícola ${ }^{45}$.

40. Idem.

41. Haji Mukhtar, Mohamed: Historical Dictionary of Somalia. Oxford: Scarecrow Press, 2003, p. 4.

42. S.a.: "Nel Benadir. Preludi dell'occupazione militare - Due scontri a Sud di Merca. La zona delle future operazioni», Bollettino della Società Africana d'Italia, Anno XXVII, Fasc. VII-VIII, julio-agosto 1908. Disponible en: http://digitale.bnc.roma.sbn.it/tecadigitale/giornale/TO00179105/1908 [Consultado el 26 de enero de 2020].

43. Haji Mukhtar, Mohamed, op. cit., 2003, p. 85.

44. Ibid., p. 149.

45. Sorrentino, G.: "Atraverso il Benadir», Bollettino della Società Africana d'Italia, Anno XXX, Fasc. XI-X, 1911, pp. 225-239, esp. p. 236. Disponible en: http://digitale.bnc.roma.sbn.it/tecadigitale/giornale/ TO00179105/1911/ [Consultado el 3 de febrero de 2020]. 
A pesar de los planes del gobernador, los hechos acaecidos en ese año llevaron a una mayor organización (sobre todo por parte de los Jama'a) y a intentar entablar relaciones con otras fuerzas como los derviches del Mullah. Aunque es cierto que Italia controlaba ya parte de la costa, no podemos hablar aún de un control absoluto de la región. Resulta lógico pensar que el estallido de la Primera Guerra Mundial dirigió los esfuerzos de Italia a luchar contra las potencias centrales, desviando su atención de la zona, lo que permitió a las resistencias reorganizarse. Así, el dominio italiano sobre el sur de Somalia no logrará consolidarse hasta la llegada del nuevo Gobernador de Somalia, Cesare Maria de Vecchi. Designado por el gobierno fascista, sustituyó en 1923 a Carli Rideri ${ }^{46}$. Vecchi tuvo que enfrentarse a los últimos levantamientos en los sultanatos de Obbia y Midyurtina. Además, durante su mandato se siguieron registrando algunas rebeliones y desordenes menores, como el ocurrido en Jubaland en $1924^{47}$.

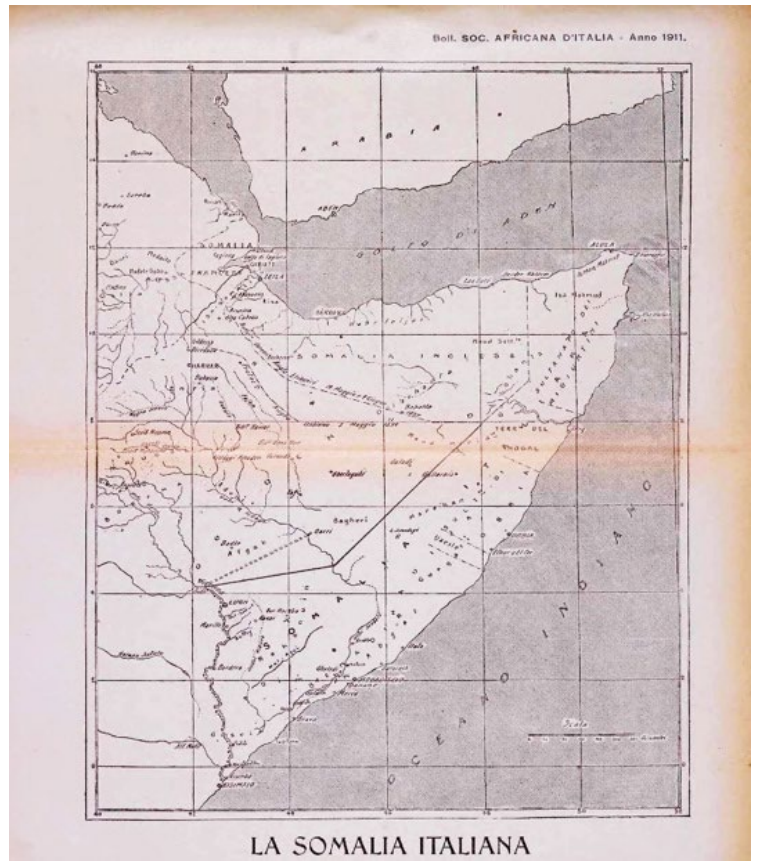

MAPA 1. SOMALIA ITALIANA (1911). Somalia Italiana, 1911,

Bollettino della Società Africana d'Italia, Anno XXX, Fasc. IX-X, 1911, p. 241

46. S.a.: "Il Governatore della Somalia», Bollettino della Società Africana d'Italia, Anno LXII, Fasc. I, 1923, p. 155. Disponible en: http://digitale.bnc.roma.sbn.it/tecadigitale/emeroteca/classic/TO00085511/1923 [Consultado el 15 de enero de 2020].

47. S.a.: "I disordini nel Giubaland», Bollettino della Società Africana d'Italia, Anno XLIV, 1925, p. 77. Disponible en: http://digitale.bnc.roma.sbn.it/tecadigitale/giornale/TO00085511/1925/ [Consultado el 15 de enero de 2020]. 


\subsubsection{Breve nota sobre las Revueltas Gosha. Una doble lucha (1890-1907)}

Aunque la Revuelta Gosha se suele analizar junto con el resto de los movimientos de resistencia del sur de Somalia hemos considerado, debido a una serie de características propias, examinar este movimiento por separado. Generalmente el término tradicional ha sido utilizado en singular, "Revuelta Gosha», pero consideramos que, de nuevo, sería necesario utilizar el plural ya que este movimiento se desarrolló a lo largo de dos décadas. Proponemos también utilizar otros términos como "Revueltas Gosha" o bien "Resistencias Gosha».

Contamos también con pocas fuentes sobre estos movimientos y las personas que lo impulsaron. No obstante, es completamente necesario realizar una breve descripción de su origen. Parece que las Revueltas Gosha estuvieron organizadas por una población de origen bantú que hablaba somalí, practicaba el islam y compartía muchos valores culturales producto de la convivencia. Su llegada a la región se debió, lo más seguro, a la introducción de esclavos durante siglos desde Zanzíbar. Los gosha eran, en su mayoría, esclavos que trabajaban para los agricultores somalíes del valle y habitaron la región que va desde Kisimayo hasta Saakow ${ }^{48}$.

La primera revuelta se inició en 1890, mucho antes de que los italianos se hubieran asentado en la zona, lo que se debió a que la lucha se dirigió contra la esclavitud que algunos líderes somalíes seguían practicando. Su principal líder, Nassib Buunto, organizó huidas masivas de comunidades de esclavos. Los esclavos que escaparon no sólo encontraron refugio y libertad, sino una vida en común en la que se dedicaron a la ganadería y a la artesanía ${ }^{49}$. A este respecto hizo mención el gobernador italiano de la Colonia de Benadir entre 1907-1908, Tommaso Carletti, en un diario publicado en 1910. Según Carletti, las orillas del Juba y el Shabelle las aldeas se componían básicamente de libertos. Si seguimos su definición, estos antiguos esclavos habitaban asentamientos estables y tendían a juntarse y reunirse con el objetivo de «defenderse de sus antiguos patrones». Se dedicaban, sobre todo, a la agricultura, pero también se dedicaban a "industrias primitivas y otros oficios». El gobernador indicó también que estos grupos «trabajaban lo suficiente para ganarse la vida», es decir, los consideraba autosuficientes ${ }^{50}$. Además de convivir en estos espacios, al parecer Buunto logró reunir a miles de soldados organizados con armas de fuego, arcos, flechas venenosas y lanzas ${ }^{51}$. De nuevo, el gobernador Carletti, indicó ese objetivo defensivo: «conservan

48. Besteman, Catherine: "The invention of Gosha: Slavery, Colonialism, and Stigma in Somali History». En: Jimale Ahmed, Ali (ed.): The invention of Somalia. Trenton: The Red Sea Press, 1995, pp. 43-62.

49. Haji Mukhtar, Mohamed, op. cit., 2003, p. 545.

50. Sorrentino, G.: "Atraverso il Benadir", Bollettino della Società Africana d'Italia, Anno XXX, Fasc. XI-X, 1911, pp. 225-239, esp. p. 228. Disponible en: http://digitale.bnc.roma.sbn.it/tecadigitale/giornale/ TO00179105/1911/ [Consultado el 3 de febrero de 2020].

51. Kendall, John George: Wiley Blackwell encyclopedia of race, ethnicity and nationalism, 2015. 
una especie de deferencia instintiva, esa deferencia que el liberado, que logró tener la tierra y el sol, siente por su antiguo amo" ${ }^{52}$.

Podría pensarse que los gosha sólo se enfrentaron a los somalíes que les habían oprimido durante décadas. Sin embargo, la resistencia de los gosha también se dirigió contra los italianos según se fueron asentando en la costa y se fueron aproximando a las zonas ribereñas. La oposición a los italianos se debió sobre todo a la confiscación de tierras y a la implantación de trabajos forzados. Los italianos trataron de justificar su presencia en esa zona con el objetivo de combatir la esclavitud. Sin embargo, el gobernador reveló algunos pareceres contradictorios. Según él, en las zonas controladas por Italia no había esclavos, pero sí existían en aquellas zonas de influencia donde no tenían el poder total. Aunque Carletti señaló que los esclavos estaban «bajo nuestra protección y vigilancia y, por diversas providencias, tratamos de mejorar gradualmente sus condiciones de existencia», lo cierto es que su apuesta por erradicar la esclavitud fue más bien nominal:

debemos limitarnos a recomendar a los amos que traten a los esclavos con humanidad, pero en esa área no intervenimos, por el momento, con mayor eficacia [...] Por ahora no se puede hacer nada más, la institución de la esclavitud corresponde a una estructura económica centenaria, que no se puede eliminar de un plumazo porque podría perjudicar al pueblo y arruinar el país ${ }^{3}$.

A pesar de la feroz resistencia, se suele considerar que la Revuelta Gosha fue derrotada en 1907 con la detención de Buunto por las fuerzas italianas ${ }^{54}$. Si bien, teniendo en cuenta que hasta 1908 los italianos no tuvieron un amplio acceso a las zonas ribereñas, parece poco probable que estas revueltas fueran aplastadas totalmente en ese año. Parece lógico pensar que los italianos fueron poniendo bajo su control a los gosha según se fueron expandiendo hacia el interior de Somalia desde 1908.

Sea como fuere, el éxito de los gosha y la importancia de su análisis radica en su capacidad de enfrentarse a dos enemigos que oprimieron a la población bajo dos fórmulas diferentes. Lograr no sólo huir sino organizarse y resistir durante casi dos décadas es todo un logro, sobre todo si pensamos que no contaban con la base organizativa previa con la que sí contaban otros grupos.

52. Sorrentino, G.: "Atraverso il Benadir", Bollettino della Società Africana d'Italia, Anno XXX, Fasc. XI-X, 1911, pp. 225-239, esp. p. 228. Disponible en: http://digitale.bnc.roma.sbn.it/tecadigitale/giornale/ TO00179105/1911/ [Consultado el 3 de febrero de 2020].

53. Ibid., p. 229.

54. Haji Mukhtar, Mohamed, op. cit., 2003, p. 149. 


\subsubsection{Las últimas resistencias: los sultanatos de Obbia y Midyurtina (1923-1927)}

La situación Septentrional de Somalia fue algo diferente a la del sur. Los sultanatos de Obbia y Midyurtina (este último también conocido como Alula) se convirtieron en protectorados de Italia el 8 de febrero de $1889^{55}$. Si bien, el control que Italia ejerció directamente sobre estos territorios fue escaso, sin un poder efectivo en ambos sultanatos. Esta falta de presencia directa hace que no se hayan registrado grandes movimientos de resistencia o lucha contra los italianos. Tiene sentido, por tanto, que la lucha se activara a partir de 1923 cuando la Somalia Italiana, dirigida por Vecchi, decida dominar de forma efectiva toda la costa de Somalia.

A pesar de que estos dos territorios habían aceptado la influencia italiana de forma más o menos pacífica en 1889, sí que se produjeron algunos conflictos. Como reflejó el diario italiano La Nazione el 6 de febrero de 1903, los italianos lograron, con engaños, detener al sultán de Obbia y su hijo, logrando que aceptaran un mayor control de Italia y abandonar su apoyo al Movimiento Derviche dirigido por Maxamed Cabdille Xassan. Esa relación entre Obbia y el Mullab era básica para el sostenimiento del Movimiento Derviche ya que, desde la costa del sultanato, Maxamed Cabdille Xassan, tenía acceso a armas y víveres ${ }^{56}$. Al parecer, las fuentes no revelan nuevos conflictos durante las dos décadas siguientes y las fuentes italianas reflejan los regulares encuentros pacíficos entre los oficiales italianos y la élite del sultanato de Obbia, como el ocurrido el 23 de diciembre de 1915 que demostraban cierto entendimiento entre ambas partes ${ }^{57}$.

Si bien esta situación se vio alterada durante la década de 1920. Ante el creciente avance de Italia, que ya controlaba la zona sur de Somalia, el sultán de Obbia trató de convencer al sultán de Midyurtina de crear un frente común contra los invasores. Sin embargo, las diferencias locales y la tradicional enemistad entre ambas partes impidieron que se fraguara un pacto. No obstante, Obbia se levantó en 1923, siguiendo el levantamiento que tuvo lugar en Midyurtina. La revuelta no duró mucho y en 1925 los italianos consiguieron imponer cierto control sobre los sultanatos, pero esto no impidió que otros movimientos de resistencia se alzaran contra los colonizadores. Tal es el caso de El Bur, en el Sultanato de Midyurtina. Esta resistencia estuvo dirigida por Umar Samatar, líder del clan majerteen, que logró dos victorias en noviembre de ese

55. S.a.: "Una residenza ad Obbia», Bollettino della Società Africana d'Italia, Anno XXVIII, 1909 Fasc. III-IV, pp. 83-84. Disponible en: http://digitale.bnc.roma.sbn.it/tecadigitale/giornale/TO00179105/1909 [Consultado el 20 de febrero de 2020].

56. S.a.: "La spedizione inglese in Somalia. Arresto dello sceicco d'Obbia», La Nazione, Anno XLV, n³7, 6 de febrero de 1905, p.1. Disponible en: http://www405.regione.toscana.it/ImageViewer/servlet/Imag eViewer?idr=TECA00000147408\#page/1/mode/2up [Consultado el 25 de mayo de 2020].

57. S.a.: "Il Sultano di Obbia decorato", Bollettino della Società Africana d'Italia, Anno XXXV, 1916, p. 76. Disponible en: http://digitale.bnc.roma.sbn.it/tecadigitale/emeroteca/classic/TO00085511/1916 [Consultado el 20 de febrero de 2020]. 
año sobre las tropas italianas. Finalmente, las fuerzas de Samatar tuvieron que huir hacia el Ogaden, cruzaron la frontera hacia Etiopía desde donde mantuvieron la lucha contra Italia ${ }^{58}$.

En 1926 Italia consiguió exiliar a Boqor Isman Mohamud y a Yusuf Ali, los sultanes de Midyurtina y Obbia, poniéndolos bajo su autoridad y trasladándolos a Mogadiscio ${ }^{59}$. Por su parte, el sultanato de Midjurtina siguió enfrentándose a Italia, rechazando de nuevo el estatus de protectorado y continuando con la lucha hasta 1927. En marzo de ese año Italia lograba completar su victoria sobre los «rebeldes de Midjurtina ${ }^{60}$.

\subsection{La amenaza derviche contra el Imperio Británico}

El Movimiento de los Derviches ${ }^{61}$ fue considerado el gran movimiento de resistencia somalí. Los derviches, encabezados por su líder Sayid Maxamed Cabdille Xasan, conocido popularmente como Mullah, lucharon contra tres poderes: italianos, británicos y etíopes.

Algunos autores han encuadrado el Movimiento Derviche dentro del "poderoso resurgir del fervor religioso islámico en toda la falla subsahariana, del Atlántico al Índico». En el caso singular del Movimiento Derviche «se debe sobre todo a la presión colonial, de la expansión etíope, a la debilidad de los sultanatos del norte del Cuerno de África y a la influencia del mahdi sudanés" ${ }^{62}$. Su cabeza visible fue Cabdille Xassan, discípulo de Saleh Rashid Sheikh ${ }^{63}$, un clérigo originario del país con el que entró en contacto durante la guerra mahdista ${ }^{64}$. Parece acertado pensar que hay algunas influencias entre el movimiento mahdista y los derviches ya que su concepción:

encaja en el esquema de las teocracias islámicas: [...] creación de una entidad política basada en una concepción rígida de las enseñanzas políticas del islam, en el ascetismo, el puritanismo e igualitarismo y en la guerra santa, como sustitución de la peregrinación a La Meca, todo ello según los cánones del mahdismo tradicional ${ }^{65}$.

58. Ibrahim, H.A.: "Politics and Nationalism...", op. cit., p. 597.

59. Haji Mukhtar, Mohamed, op. cit., 2003, p. 71.

60. S.a.: «Brillanti operazoni in Somalia contro ribelli migiurtini», Il Popolo d'Italia, Anno XIV, Num. 60, 11 de marzo de 1927 , p. 2. Disponible en: http://digiteca.bsmc.it/?l=periodici\&t=Popolo\%20d\%60Italia\%28Il\%29\# [Consultado el 24 de mayo de 2020].

61. El término derviche procede del persa darvash y hace referencia a los mendigos que ruegan a Alá. En Somalia los seguidores del Mullab tomaron este nombre por su carácter espiritual. Haji Mukhtar, Mohamed, op. cit., 2003, p. 70.

62. Caranci, Carlo, op. cit., pp. 198-199.

63. Prunier, Gérard "Segmentarité et violence dans l'espace somali, 1840-1992", Cahiers d'Études Africaines, 37(146), 1997, pp. 379-40, esp. p. 388.

64. El movimiento mahdista fue una guerra de resistencia liderado por Muhammad Ahmad, autoproclamado como Mahdi (guía) del islam, y las fuerzas egipcias y británicas que se desarrolló entre 1881 y 1899.

65. Caranci, Carlo, op. cit., pp. 203-204. 


\subsubsection{De mera resistencia a poder estatal}

El Mullah fue un predicador con una gran visión política. A su vuelta de La Meca comenzó a predicar en su tierra contra la relajación de la fe y de las costumbres, inspirado por la orden espiritual (tariqa) salehia. Entre sus planes estaban eliminar las luchas entre clanes somalíes y utilizar la violencia contra los invasores, uniendo a los pueblos somalíes a través de los vínculos religiosos. De este modo, en 1899, se rebelarán contra los británicos, arengando a pastores y agricultores a luchar contra los colonizadores. En tan sólo unos meses eran miles los guerreros que seguían al Mullah atraídos por su particular renovación islámica mística y puritana ${ }^{66}$. Hamilton, el joven periodista británico contemporáneo de estos hechos, reflexionó sobre cuál fue la razón que, según él, dio tantas alas a Maxamed Cabdille Xassan:

Predicaba de forma continua en Berbera y otros lugares [...] y poco a poco obtuvo la reputación y la influencia de un hombre sagrado [...] El error se debió a concederle una libertad de expresión extraordinaria y el hecho de que gozara de cierta inmunidad aumentó su influencia, incluyendo bajo su mandato a las tribus del interior ${ }^{67}$.

El movimiento pronto amenazó con invadir Berbera, el principal puerto comercial del protectorado británico y un punto clave que abastecía a sus flotas. Como respuesta, el Imperio británico lanzó cuatro campañas militares para destruir el Movimiento Derviche entre 1900 y $1904^{68}$. Sin embargo, el balance fue negativo: Gran Bretaña había entrado en una guerra sin sentido en el desierto de Somalia que le había costado numerosas pérdidas humanas y militares. Se estaba pagando un alto precio sobre todo si pensamos que los británicos no tenían interés en el interior de la colonia, sino en mantener los puertos y el control de la costa ${ }^{69}$. De nuevo, Hamilton hizo referencia a la expansión de los derviches durante este periodo: "[el Mullah] dominaba el sur de nuestro protectorado, así como una parte considerable de las esferas de Italia y Abisinia, y su expulsión se había convertido en un objetivo prioritario» ${ }^{70}$.

No obstante, el rápido ascenso de los derviches chocó en 1904 con el avance etíope y en ese mismo año fueron derrotados por primera vez frente a los británicos en Jidbaley. El Mullah optó por firmar un acuerdo de paz con italianos y británicos, el denominado Tratado de Illig, en virtud del cual se le otorgaba el control sobre una región del interior, el Nogal, y el pequeño puerto de Eyl, en el Océano Índico. Tal y como se puede ver en el acuerdo firmado, el Mullab aceptaba mantener la paz

66. Ibid., pp. 199-200.

67. Hamilton, Angus, op. cit., p. 49.

68. KaKwenzire, Patrick: "Resistance, Revenue and Development in Northern Somalia, 1905-1939", The International Journal of African Historical Studies, 19, 1986, pp. 659-677, esp. p. 662.

69. Ibid., pp. 663-664.

70. Hamilton, Angus, op. cit., p. 53. 
con italianos, británicos y etíopes a cambio de conseguir el reconocimiento de este territorio en la costa este de Somalia y el acceso a pastos y a agua en el territorio del Somaliland británico ${ }^{71}$. A pesar de controlar una región pequeña y de escaso interés para las potencias coloniales, el tratado de Illig supuso un punto de inflexión en la constitución del Estado Derviche.

Ciertamente, las potencias europeas y Etiopía habían reconocido la existencia de este territorio como una región independiente. Aunque existía una cláusula que teóricamente demarcaba el territorio como un "protectorado bajo el dominio italiano" lo cierto es que la presencia de Italia fue nula, lo que permitió al Mullah actuar libremente. Este reconocimiento fue utilizado por Maxamed Cabdille Xassan para poner en marcha sus ambiciones de construcción estatal en las que incluso se proyectó desarrollar una pequeña flota mercante y el impulso a una política marítima ${ }^{72}$.

El medio británico The Times recogió algunos detalles más de las condiciones del Tratado de Illig en un artículo publicado días después de que se firmara el acuerdo. Este documento señala que las negociaciones fueron lideradas por el diplomático italiano Pestalozza que propuso las cláusulas en nombre del gobierno italiano y en interés del gobierno de Gran Bretaña. Según este medio, el Tratado reconocía el derecho del Mullah a ocupar el territorio que recaería bajo la fórmula del protectorado de Italia ${ }^{73}$. Igualmente, en otro artículo publicado el 15 de abril de 1905 se volvía a hacer referencia al acuerdo y se insistía en que el territorio sería protectorado italiano. No obstante, se reconocía al Mullah como el administrador del territorio sobre el que recaería "toda la responsabilidad». Ese mismo artículo señalaba la incapacidad de Italia de mantener una guerra contra los derviches como la que había realizado Gran Bretaña en los últimos cinco años y por ello se esforzaron en conseguir un acuerdo de paz ${ }^{74}$. Este tratado también reflejó, como señaló el diario La Nazione, la buena sintonía entre los

71. "Agreement of Peace and Protection between Italy and the Mullah of the Somalis (Africa)" Illig, 5 de marzo de 1905, Oxford Historical Treaties. Disponible en: https://opil.ouplaw.com/view/10.1093/law:oht/ law-oht-198-CTS-137.regGroup.1/law-oht-198-CTS-137 [Consultado el 25 de febrero de 2020].

72. Kapteijns, L.: "A letter from Sayyid Muhammad 'Abd Allah Hassan to the British Governor of Somaliland, June 1905", Sudanic Africa, 6, 1995, pp. 1-10, esp. p. 1.

73. S.a.: "Somaliland. Italian agreement with the Mullah", The Times, 19 de marzo de 1905, p. 3. Disponible en: https://www.thetimes.co.uk/archive/article/1905-03-20/3/7.html?region=global\#start\%3D190501-01\%26end\%3D1905-12-12\%26terms\%3DIllig\%26back\%3D/tto/archive/find/Illig/w:1905-01-01\%7E190512-12/1\%26next\%3D/tto/archive/frame/goto/Illig/w:1905-01-01\%7E1905-12-12/2 [Consultado el 22 de mayo de 2020].

74. S.a.: "Italy and the Mullah", The Times, 15 de abril de 1905, p. 7. Disponible en: https://www. thetimes.co.uk/archive/article/1905-04-15/7/15.html?region=global\#start\%3D1785-01-01\%26end\%3D1985-1231\%26terms\%3DMullah\%26back\%3D/tto/archive/find/Mullah/w:1785-01-01\%7E1985-12-31/1\%26next\%3D/tto/ archive/frame/goto/Mullah/w:1785-01-01\%7E1985-12-31/2 [Consultado el 22 de mayo de 2020]. 
gobiernos de Inglaterra e Italia, que estaba permitiendo poner bajo control el Cuerno de África de las dos administraciones coloniales ${ }^{75}$.

De este modo, nos debe asaltar una duda sobre el Tratado de Ilig: ¿se reconocía el territorio derviche como un territorio independiente o aceptaba el Mullab la fórmula del protectorado? Es evidente que, aunque el acuerdo recogía la creación de un protectorado, esa fórmula no llegó nunca a fraguarse debido a que las fuerzas italianas no tenían capacidad ninguna sobre el territorio. Pensemos que, en 1905, la presencia italiana era testimonial, y más allá de la zona próxima a Mogadiscio su control efectivo era inexistente. De esta forma, Cabdille Xassan salió de aquel concordato totalmente reforzado: su autoridad era reconocida tanto por Gran Bretaña como por Italia y la paz firmada le permitía cierto margen de reorganización.

\subsubsection{El Movimiento Derviche: ¿una alternativa al poder colonial?}

En este punto debemos replantearnos si los derviches fueron una alternativa real al poder colonial. En primer lugar, el movimiento de los derviches mantuvo una organización encabezada por una única figura, la del Mullah. Además, Cabdille Xassan tuvo la capacidad real de controlar un territorio determinado y aunque sus dimensiones fueron variando, sí podemos afirmar que se convirtió en una amenaza real para los intereses de los colonizadores.

A pesar de que para los poderes imperiales resultaba intolerable que existiera una organización independiente que permitiera a los somalíes identificarse con una alternativa política a la colonia ${ }^{76}$, la situación les obligó a permitir que estos tuvieran su espacio político, al menos temporalmente. La habilidad del Mullah y sus seguidores de obtener reconocimiento por parte de Italia y Gran Bretaña, les convirtió en un actor con la legitimidad para entablar una nueva relación con otros estados, un hecho que les funcionó como un revulsivo moral para sus aspiraciones. Pero debemos de ser cautos: los recursos materiales y humanos eran limitados; su situación geopolítica, rodeados por tres enemigos con una potencia militar muy elevada, no les era favorable y el control de facto de los poderes europeos en sus respectivas colonias era cada vez mayor, lo que complicaba su supervivencia a largo plazo.

No obstante, desde 1905 los derviches habían optado por reorganizarse. El Mullah buscó la alianza de otros clanes somalíes y su influencia alcanzó todo el centro de la región, así como algunas zonas del sur y del norte. Ya en 1902 una carta enviada por parte de Rennell Rodd, embajador británico en Roma, a M. Prinetti, Ministro de Asuntos

75. S.a.: "Il Trattato col Mad Mullah", La Nazione, Anno XLVII, nº 80, 21 de marzo de 1905, p. 3. Disponible en: http://www405.regione.toscana.it/ImageViewer/servlet/ImageViewer?idr=TECA00000173897 \#page/1/mode/2up [Consultado el 24 de mayo de 2020].

76. GeshekTer, C. L., op. cit., p. 17. 
Exteriores de Italia, alertaba de que era «estratégica y políticamente necesario detener la expansión de Mullab hacia el sur» y acordaba el desembarco de tropas británicas en Obbia, zona de influencia italiana ${ }^{77}$. Aunque el período 1905-1908 fue tranquilo, lo cierto es que tan sólo unos meses después de que se firmara el Tratado de Illig se comenzaron a registrar algunos disturbios puntuales en la región controlada por el Mullah, junto con otras revueltas registradas en el sultanato de Midyurtina ${ }^{78}$. Si bien, el año que marcó el punto de inflexión y que reinició las actividades de los derviches fue 1908. Desde ese año se registraron continuos ataques al sultanato de Obbia, supuestamente bajo control de Italia. Según The Times, los derviches "penetraron en el sultanato y asesinaron a 41 hombres, 28 mujeres, 31 niños y robaron 3500 cabezas de ganado. Eran una fuerza de 1050 hombres, 500 de los cuales estaban armados con rifles» ${ }^{79}$.

Desde ese año, los británicos fueron perdiendo el control del territorio y quedaron reducidos a la zona costera. De hecho, entre 1909-1910 se decidió la evacuación de los territorios internos de la colonia, pasando a tener sólo el control de los principales núcleos urbanos y de la costa ${ }^{80}$. La situación no mejoró tras el estallido de la Primera Guerra Mundial. Al igual que había ocurrido en la zona italiana, la distracción del conflicto dio un nuevo impulso al Movimiento Derviche. De hecho, The Times recogió el aumento de la presión de los derviches en la colonia británica desde principios de 1914 al señalar que los seguidores del Mullah estaban muy "activos y agresivos» y que se estaban acercando peligrosamente al puerto de Berbera ${ }^{81}$.

Pero, además, el Mullah contó con un aliado inesperado. El emperador etíope Menelik II había muerto el 12 de diciembre de 1913, y la sucesión del trono recayó en

77. Hamilton, Angus, op. cit., pp. 159-177.

78. S.a.: "Italian Somaliland», The Times, 18 de octubre de 1905, p.3. Disponible en: https://www. thetimes.co.uk/archive/article/1905-10-18/3/7.html?region=global\#start\%3D1785-01-01\%26end\%3D1985-1231\%26terms\%3DMullah\%26back\%3D/tto/archive/find/Mullah/w:1785-01-01\%7E1985-12-31/10\%26prev\%3D/ tto/archive/frame/goto/Mullah/w:1785-01-01\%7E1985-12-31/97\%26next\%3D/tto/archive/frame/goto/Mullah/ w:1785-01-01\%7E1985-12-31/99 [Consultado el 22 de mayo de 2020].

79. S.a.: "The Fighting in Italian Somaliland», The Times, 10 de abril de 1908, p.5. Disponible en: https:// www.thetimes.co.uk/archive/article/1908-04-11/5/23.html?region=global\#start\%3D1785-01-01\%26end\%3D198512-31\%26terms\%3DMullah\%26back\%3D/tto/archive/find/Mullah/w:1785-01-01\%7E1985-12-31/8\%26prev\%3D/ tto/archive/frame/goto/Mullah/w:1785-01-01\%7E1985-12-31/79\%26next\%3D/tto/archive/frame/goto/Mullah/ w:1785-01-01\%7E1985-12-31/81 [Consultado el 22 de mayo de 2020].

80. S.a.: "Somaliland", Actas del Parlamento Británico, Cámara de los Comunes, 5 de abril de 1910, Vol. 16. Disponible en: https://hansard.parliament.uk/Commons/1910-04-05/debates/f1b9a42e-5ecb-4f92ba2c-b5b65f52dca4/Somaliland [Consultado el 22 de mayo de 2020].

81. S.a.: "The Dervish Danger in Somaliland. Increase of protective forces", The Times, 16 de marzo de 1914, p. 7. Disponible en: https://www.thetimes.co.uk/archive/article/1914-03-17/7/5.html?region=global\#start\%3D178501-01\%26end\%3D1985-12-31\%26terms\%3DMullah\%26back\%3D/tto/archive/find/Mullah/w:1785-01-01\%7E198512-31/7\%26prev\%3D/tto/archive/frame/goto/Mullah/w:1785-01-01\%7E1985-12-31/66\%26next\%3D/tto/archive/ frame/goto/Mullah/w:1785-01-01\%7E1985-12-31/68 [Consultado el 22 de mayo de 2020]. 
Lij Yasu que gobernó nominalmente el Imperio entre 1913-1916. En el transcurso de la Gran Guerra, Iyasu V se inclinó hacia los Imperios Centrales, a los que apoyó de forma activa y buscó un aliado regional en el Estado Derviche ${ }^{82}$. No es de extrañar que Iyasu, al verse rodeado por las fuerzas de británicos, franceses e italianos, buscara una alianza alternativa con otros imperios que no tenían intereses coloniales o no habían invadido Etiopía, como era el Imperio Alemán, el Imperio Austrohúngaro o el Imperio Otomano. La necesidad de expulsar a las potencias coloniales forjó una extraña alianza que llegó incluso a proyectar la invasión turco-derviche de Berbera y la expulsión británica en 1916 $6^{83}$. No obstante, las nuevas políticas de aproximación al islam impulsadas por Lij Yasu provocaron toda una serie de protestas en Etiopía que llevaron al abuna etíope a destituirlo, nombrando regentes a la hija de Menelik, Zauditu I, y al futuro emperador Haile Selassie en septiembre de $1916^{84}$. Ante estos hechos, el embajador británico en Etiopía anunciaba a la Foreign Office que «el gobierno está ahora en manos de aquellos que son proclives a nuestra causa ${ }^{85}$.

A pesar de la derrota estratégica que supuso la retirada de Etiopía en 1916, el reconocimiento que recibió el movimiento como factor militar crucial para los planes de los Imperios Centrales en el Cuerno de África creó una imagen de seguridad y una regeneración moral sin precedentes. Si bien, la concepción que el Mullah tenía de su posición en la arena internacional no era una valoración real y el estatus del Estado Derviche era mucho menor ${ }^{86}$. Un hecho que se materializó en la aplastante derrota que sufrió el movimiento poco después.

Una vez terminada la Gran Guerra, los británicos tuvieron la capacidad de movilizar los recursos suficientes para acabar con el Estado Derviche. En febrero de 1920 bombardearon sus principales posiciones, incluyendo Taleh, considerada la capital. El propio Subsecretario de Estado para las Colonias, el Teniente-Coronel Amery, hizo referencia a los bombardeos en el Parlamento británico:

El 6 de febrero se interceptó al grupo del Mullah que había sido desorganizado por el bombardeo aéreo, capturando grandes cantidades de material y rifles, así como los efectos personales del Mullah y su oficina. El propio Mullah escapó al fuerte de Tale. Esta posición (que era de hecho una ciudad amurallada rodeada por 13 fuertes) ya había

82. Zewde, Bahru: «Iyasu». En: UHLIG, Siegbert (ed.): Encyclopaedia Aethiopica, Vol. III. Wiesbaden: Harrasowitz, 2007, pp. 253-256.

83. PAICE, E.: Tip and Run: the untold tragedy of the Great War in Africa. Londres: Weidenfeld \& Nicolson, 2007.

84. S.a.: "La destituzione di Ligg Yasu», Bollettino della Società Africana d'Italia, Anno XXXV, 1916, p. 223. Disponible en: http://digitale.bnc.roma.sbn.it/tecadigitale/emeroteca/classic/TO00085511/1916 [Consultado el 20 de febrero de 2020].

85. KakwenZaire, Patrick: "Sayyid Muhammad Abdille Hassan, Lij Yasu and the World War I Politics: 1914 - 1916", Transafrican Journal of History, 14, 1985, pp. 36-45, esp. p. 44.

86. KaKWENZIRE, Patrick, op. cit., 1996, p. 668. 
sido bombardeada e incendiada por aviones en días anteriores. Ahora estaba rodeada y, a pesar del enorme grosor de las fortificaciones y las murallas, fue capturada por ellos el 9 de febrero. El propio Mullah, con un pequeño grupo de unos 70 jinetes, escapó, pero el resto de los derviches de los fuertes se rindieron o fueron capturados, y se incautaron grandes cantidades de existencias y armas ${ }^{87}$.

Aunque el Mullab no había sido capturado, ni había muerto en los enfrentamientos, la confirmación de su fallecimiento por muerte natural en Ogaden, tuvo lugar en 1921 cuando el Estado Derviche ya había desaparecido ${ }^{88}$. Se ponía así fin a uno de los movimientos de resistencia más potentes que se desarrollaron en el Cuerno de África.

\section{CONCLUSIONES}

A lo largo de esta investigación se ha realizado un análisis de las resistencias que existieron en la región del Cuerno de África. Aunque tradicionalmente los estudios sobre las resistencias somalíes se han centrado en estudiar el Movimiento Derviche, hemos visibilizado una realidad mucho más diversa.

Nadie niega hoy que el Estado Derviche fuera el movimiento que mayor resistencia opuso a los imperios europeos y etíope, pero eso no impide abrir la mirada a otros procesos. Así, las resistencias del sur formaron otro tipo de oposición a las fuerzas invasoras. Además, no podemos pasar por alto que, teniendo en cuenta que los pueblos del sur iniciaron la lucha y resistencia en 1896 y que los sultanatos de Obbia y Midyurtina resistieron hasta 1927, estos movimientos nacieron antes que el Movimiento Derviche y se desarrollaron durante más tiempo. Toda esta diversidad responde a las diferentes realidades que convivieron en Somalia a finales del siglo XIX y que se corresponden con los contextos históricos, políticos, económicos, sociales y culturales particulares de cada región.

Es un hecho que el Estado Derviche fue el mayor exponente somalí de lucha y resistencia contra el poder colonial y el movimiento que llegó a considerarse toda una amenaza. La clave del movimiento radica en su competencia para convertirse en una alternativa política a la colonización. Sin duda alguna, el contexto internacional

87. "Successful operations against Mullah", Actas del Parlamento Británico, 17 de febrero de 1920, Vol. 125. Disponible en: https://hansard.parliament.uk/Commons/1920-02-17/debates/0cc406be-0086-41c88022-a9c16845e9a5/SuccessfulOperationsAgainstMullah?highlight=mullah\# contribution-c81a5a2f-4a19-44e291e9-90437b0f2de7 [Consultado el 21 de febrero de 2020].

88. S.a.: "The Mad Mullah: His death Confirmed", The Times, 18 de septiembre 1921, p. 7. Disponible en: https:// www.thetimes.co.uk/archive/article/1921-09-14/7/17.html?region=global\#start\%3D1921-01-01\%26end\%3D192112-01\%26terms\%3DMullah\%26back\%3D/tto/archive/find/Mullah/w:1921-01-01\%7E1921-12-01/1\%26prev\%3D/ tto/archive/frame/goto/Mullah/w:1921-01-01\%7E1921-12-01/2\%26next\%3D/tto/archive/frame/goto/Mullah/ w:1921-01-01\%7E1921-12-01/4 [Consultado el 25 de mayo de 2020]. 
marcado por la Gran Guerra ayudó al sostenimiento de los derviches, pero las estrategias del Mullah para construir un Estado propio dentro del Cuerno de África representan también todo un ejemplo de organización.

No obstante, no podemos caer en el error de que el Movimiento Derviche pueda acabar eclipsando a los otros procesos de resistencia ya que las revueltas del sur de Somalia evitaron la implantación de la administración italiana durante años. Frente a la imagen de una Somalia dominada a finales del siglo XIX, la realidad demuestra que hasta 1908 Italia no tuvo el control de la franja costera y que hasta 1923 no dominó totalmente todo el sur de Somalia. Además, la colonia de la Somalia Italiana no fue una realidad hasta el dominio sobre los sultanatos septentrionales en 1927.

Todo esto nos demuestra, además, que las resistencias del Cuerno de África no se basaron únicamente en el islam como eje de actuación. Aunque este tuviera un papel clave en muchos ámbitos, las causas de las resistencias parecen ser mucho más variadas. El Estado Derviche sí que centró su reacción en la renovación de un islam puro, pero los levantamientos de los sultanatos, por ejemplo, tenía más que ver con una reacción política. En el caso de las resistencias del sur de Somalia la reacción nació como respuesta a la confiscación de tierras por parte de los italianos, la extensión de los trabajos forzados y la alteración de su modelo productivo. Como vemos, las razones que llevaron a levantarse a los pueblos de Somalia fueron muy dispares.

Por último, resulta esencial destacar que, a pesar de que Somalia acabó por ser dominada totalmente por los poderes europeos, sus pueblos consiguieron retrasar el completo dominio hasta casi la década de 1930. Además, tan sólo veinte años más tarde comenzaron a nacer los primeros movimientos independentistas muchos de los cuales se inspiraron en las resistencias que sus antecesores habían planteado desde finales del siglo XIX. 